\title{
Expectativas sobre o desenvolvimento da carreira em estudantes universitários
}

\author{
Reivani Chisté Zanotelli Buscacio ${ }^{1}$ \\ Universidade Veiga de Almeida, Rio de Janeiro-RJ, Brasil \\ Adriana Benevides Soares \\ Universidade Salgado de Oliveira, Niterói-RJ, Brasil
}

\section{Resumo}

Este estudo objetivou identificar, a partir do discurso dos estudantes, as expectativas relacionadas à escolha profissional e reconhecer as influências sociais que estão subjacentes às escolhas. Foram entrevistados cinco estudantes, de ambos os sexos, de diferentes idades e períodos de universidades públicas e privadas do estado do Rio de Janeiro. Para tal, foi utilizada metodologia qualitativa com um roteiro de entrevista semiestruturada construída especialmente para este estudo. Pode-se concluir que parte dos estudantes universitários mostrou ter expectativas claras, pouco fantasiosas, quanto à carreira que escolheram seguir, não se deixando influenciar por um discurso social ainda conservador. Além disso, a maioria reconhece suas próprias características, necessidades e desejos, categoria denominada aqui como autoconhecimento.

Palavras-chave: expectativas, estudantes universitários, escolha profissional, carreira, estudo qualitativo

\section{Abstract: University students and their expectations about career development}

This study aimed to identify, from the students' discourse, the expectations related to the professional preference and recognize the social influences underlying these preferences. Five students of sexes, different ages and periods of public and private universities of the state of Rio de Janeiro were interviewed. With that purpose, a qualitative methodology was used with a semi-structured interview script specially designed for this study. It is possible to conclude that some of the university students showed to have clear, unrealistic expectations as to the career that they chose to follow, not being influenced by a still conservative social discourse. Moreover, most of them recognize their own characteristics, needs and desires, a category termed here as self-knowledge.

Keywords: expectations, university students, professional choice, career, qualitative study

\section{Resumen: Expectativas sobre el desarrollo de carrera en estudiantes universitarios}

Este estudio tuvo como objetivo identificar, a partir del discurso de los estudiantes, las expectativas relacionadas con la elección profesional y reconocer las influencias sociales subyacentes a estas decisiones. Fueron entrevistados cinco estudiantes de ambos sexos, de diferentes edades y semestres de universidades públicas y privadas del estado de Rio de Janeiro. Para ello, fue utilizada la metodología cualitativa con una guía de entrevista semiestructurada elaborada específicamente para este estudio. Se puede concluir que parte de los estudiantes universitarios tienen expectativas claras con relación a la carrera que eligieron y no se dejan influenciar por un discurso social aún conservador. Además de ello, la mayoría reconoce sus propias características, necesidades y deseos, lo que entendemos como auto-conocimiento.

Palabras clave: expectativas, estudiantes universitarios, elección profesional, carrera, estudio cualitativo

\footnotetext{
${ }^{1}$ Endereço para correspondência: Rua Ibituruna, 108, Maracanã, 20271-020, Rio de Janeiro-RJ. E-mail: reivani@gmail.com
} 
Eleger uma carreira é considerada uma opção que muitos jovens fazem em busca da independência financeira ou da realização pessoal. A adolescência, nesse contexto, é um período do ciclo de vida no qual os indivíduos são confrontados com a necessidade de fazerem escolhas e estabelecerem planos para o futuro profissional. Porém, muitas vezes, ainda encarada como "decisiva para a vida toda", a decisão por uma carreira acontece a partir de escolhas feitas em uma etapa da vida em que o estudante ainda não possui as condições necessárias para avaliar, as perspectivas dos acontecimentos que o aguardam durante e após o término de seu curso. Por isso, o processo decisional não deve ser considerado um método rígido, tampouco linear (Gadassi, Gati, \& Dayan, 2012; Gati, 2013). Por outro lado, a decisão vem permeada de expectativas construídas ao longo de seu ciclo de vida, (Super, Savickas, \& Super, 1996; Super, 1990) a partir do autoconhecimento e de influências sociais tais como familiares, amigos, professores e da mídia. Destarte, o comportamento exploratório, termo cunhado por Jordaan (1963) e estudado por Super (1963), tem sido fomentado e explorado por Teixeira, Bardagi e Hutz (2007) e Teixeira e Dias (2011) como um aspecto importante do estágio evolutivo de desenvolvimento vocacional e do processo de decisão de carreira, a partir do qual, por assim dizer, é realizado um mapeamento das características internas (self exploration) e externas (environmental exploration) do indivíduo. No entanto, embora os autores considerem a exploração um estágio do desenvolvimento vocacional, ele parece não ocorrer da mesma forma para todos os indivíduos visto que, na maioria das vezes, não sabem se o curso escolhido é o mais adequado para seu perfil ou para realização de suas aspirações pessoais. Este fato tem sido evidenciado ou pelo processo de indecisão apresentado nos estudos de Faria e Taveira (2006); Lassance, Bardagi e Teixeira, (2009) e Sparta (2003) ou pela troca de curso no primeiro ano de graduação (Felix, 2013). Nesse sentido, entender como as escolhas são afetadas pela dinâmica de elementos sociais e pessoais pode contribuir para um desenvolvimento de carreira pautado em condições mais próximas às necessidades do estudante oferecendo-lhe maior autonomia frente às decisões (Lent, Brown, \& Hackett, 1994; Teixeira, 2008). Este modelo sociocognitivo contempla o aspecto longitudinal da escolha no qual o indivíduo aprende ao longo de toda a vida a partir de informações contidas no meio em que vive e também graças ao autoconhecimento.

As expectativas que os estudantes possuem sobre a universidade e sobre seu futuro profissional podem ser considerados um tema complexo, não só por se tratar de uma população heterogênea como, por exemplo, em relação à faixa etária, aos objetivos de vida pessoal e profissional, como também pelo caráter dinâmico, do contexto social em que está inserido. Atualmente, os cursos universitários são preenchidos tanto por adolescentes que acabaram de sair do Ensino Médio quanto por pessoas que buscam uma recolocação no mercado de trabalho. Assim, se por um lado as expectativas são as predições acerca do desempenho em determinado contexto social (Gomes \& Soares, 2013); por outro lado, deve-se levar em consideração que a formação de tais predições é permeada por um contexto sócio-histórico-cultural que pode exercer algum tipo de influência sobre o que se espera da vida acadêmica (Berger \& Luckman, 2004; Faria \& Loureiro, 2015; Setton, 2011; Teixeira, 2008).

Por vezes, pessoas fazem suas escolhas de carreira de forma irrealista, conhecendo pouco sobre a totalidade das implicações das mesmas em termos de tarefas, dificuldades e responsabilidades (Gomes \& Soares, 2013). Além disso, a família, a escola e a sociedade, muitas vezes influenciam a decisão do adolescente, seja para motivá-lo a seguir a carreira dos pais, seja para estimulá-lo a seguir a "carreira da moda" que tem, como plano de fundo, o mercado de trabalho em crescimento em algumas áreas (Aguiar \& Conceição, 2009; Bardagi, Lassance, \& Paradiso, 2003). Tanto de uma forma como de outra, muitas vezes a pessoa opta por uma carreira que "não escolheu" de fato. A ausência do movimento de investigação e do pensamento crítico acabam por prejudicar aprendizagens essenciais na vida, entre elas, a de saber lidar com situações de escolha (Neiva, 2013), de desenvolver habilidades de exploração e de tomada de decisão (Gadassi, Gati, \& Dayan, 2012; Gati, 2013; Oliveira \& Dias, 2013; Teixeira, Bardagi, \& Hutz 2007; Teixeira \& Dias, 2011). Nesse sentido, sujeitos que têm menos vivências acadêmico/profissionais, que buscam poucas informações sobre o curso e que não conversam com profissionais da área apresentam expectativas menos realistas do Ensino Superior (Gomes \& Soares, 2013) e, consequentemente, encontram maiores dificuldades em lidar com as novas situações que o contexto exige. Por outro lado, expectativas mais realistas sobre o curso (Hernández \& Pérez, 2010) e sobre a instituição (Nadelson et al., 2013), geralmente atribuídas àqueles que têm mais conhecimento sobre a vida universitária, podem contribuir para a permanência e conclusão do curso levando-os a um compromisso em relação à profissão (Freund, Cohen, BlitCohen, \& Dehan, 2013).

Dessa forma, o engajamento do estudante frente ao curso que escolheu trilhar favorece o desenvolvimento de expectativas mais próximas à realidade profissional. Engajar-se, no sentido de alinhar-se com as características do curso, pode facilitar a compreensão 
do desenvolvimento da carreira. Além disso, é relevante atentar para os aspectos individuais e para as mudanças produtivas e sociais ocorridas, especialmente a partir da década de 1990, e seu impacto sobre as escolhas de carreira. A lógica de mercado inaugurada nesse período reflete, cada vez mais, nas atitudes e percepções das pessoas. Faz com que estas escolham, embasadas em valores diferentes daqueles que são tradicionalmente conhecidos, como estabilidade, segurança, emprego fixo, planejamento em longo prazo. Tais aspectos vêm sendo, senão substituídos, deixados de lado a favor da flexibilidade, da mobilidade do planejamento e dos projetos em curto prazo (Zanotelli, 2009). Certamente, tais mudanças irão repercutir nas expectativas acadêmicas, geradas na entrada da universidade, nas escolhas profissionais, uma vez que surgem novas carreiras e outras deixam de existir. Vale ressaltar que mesmo as carreiras mais tradicionais acabam tendo que se ajustar a um novo modelo econômico-social e, por conseguinte, as expectativas.

Segundo Hila (2014), expectativas englobam as crenças, valores, motivações e interesses, emoções e os comportamentos. Podem ser entendidas como predições que a pessoa faz em relação ao seu desempenho em determinado contexto social para atender não só às suas necessidades como as do outro. As expectativas induzem a pessoa a selecionar ações dentre a variedade de repertórios de habilidades que possui para corresponder satisfatoriamente às demandas pessoais e sociais (Gomes \& Soares, 2013). Nesse sentido, a ausência de conhecimento dos aspectos culturais relacionados à prática profissional pode dificultar o processo de escolha, uma vez que decidir uma carreira não implica, exclusivamente, a análise do curso em si, mas inclui também as possibilidades de trabalho que o estudante terá, seus proventos, assim como o tipo de estilo de vida que deseja para seu futuro (Araújo et al., 2015). Além disso, estudo como o de Bardagi et al. (2003) mostra que a participação do estudante na construção da sua carreira pode contribuir para gerar expectativas relacionadas à carreira e ao futuro profissional.

Quanto à participação ativa no desenvolvimento da própria carreira, uma das conclusões do estudo de Bardagi et al. (2003), que teve como objetivo investigar a trajetória acadêmica, satisfação com a escolha profissional e expectativas quanto à orientação profissional, evidenciou algumas repercussões da rotina universitária. Mostrou que, quando os estudantes são envolvidos e participam, ao longo da sua formação, de estágio ou de outras atividades que envolvem a área escolhida, tendem a fazer uma conexão melhor entre a teoria e a prática, o que reforça a satisfação com a escolha feita. Ao contrário, os estudantes pouco comprometidos em atividades tais como palestras, workshops, visitas técnicas, ou outras tarefas, apresentam menos satisfação e indicam que já pensaram em desistir ou mudar de profissão (Bardagi et al., 2003).

Muitas vezes, a escolha da carreira vem recheada de expectativas em relação ao futuro na universidade e, posteriormente, ao futuro profissional (Soares et al., 2014). As preocupações mais frequentes são com a adaptação ao curso, aos professores, aos colegas de turma, dúvidas sobre disciplinas e estágios que irão contribuir para a sua formação, como será sua entrada no mercado de trabalho, se irá lhe render um salário estável e uma vida confortável (Soares, 2002). Nesse sentido, pensar no futuro pode representar para os estudantes, quase que imediatamente, o medo do desconhecido, pois as expectativas sobre uma profissão podem surgir juntamente com o medo do fracasso (Soares, 2002). Para minimizar esse sentimento, muitas vezes, os pais acabam orientando seus filhos para uma profissão que consideram tradicionalmente mais estável, mais segura financeiramente, porém deixam de considerar que as carreiras são regidas por outra lógica de mercado globalizada, que exige maior mobilidade e flexibilidade e pelo surgimento de novos cursos e modelos acadêmicos, que podem ser tão interessantes e promissores quanto os tradicionais (Soares, 2002).

Segundo Merhi (2011), expectativas sobre a universidade estão relacionadas ao que o estudante espera obter/alcançar. Para isso, é necessário que o sujeito tenha conhecimento prévio do que a universidade tem a lhe oferecer nos âmbitos acadêmico e extra-acadêmico. Desse modo, segundo o autor, os conceitos de expectativa e participação acadêmicas estão, de forma bidirecional, intimamente relacionados. Ainda sobre as expectativas na universidade, Merhi (2011) questiona quais podem ser as razões que levam o estudante a escolher uma carreira. A resposta é atribuída à relação positiva que existe entre a formação universitária e a empregabilidade. Entre os fatores apresentados pelo autor e que explicam parte dessa relação, destacam-se o interesse pessoal (fator interno, pessoal) e a crise econômica (fator externo, social) (Teixeira, Bardagi, \& Hutz 2007; Teixeira \& Dias, 2011). O primeiro refere-se ao interesse da pessoa por uma área de conhecimento específica que é traduzida, segundo o autor, em uma vocação pessoal relacionada à disciplina que a titulação lhe será conferida. Em relação ao contexto social, devem ser levados em consideração fatores econômicos e políticos.

A relação entre a formação universitária e a empregabilidade também pode ser compreendida a partir de Castro, Nishimura, Silva, Madureira e Casado (2007). Em ambos os estudos, o de Castro et al. (2007) e o de Merhi (2011), há uma expectativa do estudante 
de que, na universidade, consiga fazer uma ponte entre o conhecimento teórico e a prática, ou seja, que a universidade lhe dê a oportunidade de se desenvolver e de adquirir conhecimento suficiente para o exercício profissional.

A partir dos estudos apresentados, o que se observa, na literatura, é que há um interesse crescente em investigar as expectativas dos estudantes universitários, seja identificando-as no ingresso no Ensino Superior (Gomes \& Soares, 2013; Soares et al., 2014) seja na construção e adaptação de instrumentos para aferi-las (Marinho-Araújo, Fleith, Almeida, Bisinoto, \& Rabelo, 2015; Soares \& Almeida, 2001) além da diferenciação de expectativas relacionadas a variáveis pessoais e socioculturais de estudantes do Ensino Superior (Araújo et al., 2015). No entanto, diante à dinamicidade do contexto social permeado por mudanças econômicas e educacionais, faz-se importante investigar como aspectos sociais podem contribuir para a escolha de uma carreira. Se, por um lado, esse cenário favorece a entrada de pessoas nas universidades vindas de classe socioeconômica baixa e de grupos minoritários, por exemplo, por outro, contribui para o aumento dos possíveis fatores que as levam a fazer determinadas escolhas, aumentando, consequentemente, a necessidade de se compreenderem as diferentes expectativas e motivações a elas vinculadas.

Dessa forma, considerando a natureza multidimensional das expectativas atrelada a um contexto social dinâmico, faz-se importante investigar, adicionado às motivações do próprio sujeito, como as influências sociais, pautadas no modelo teórico de French e Raven (1959), contribuem para a formação das expectativas a fim de que, com esse conhecimento, se possa empoderar o estudante no processo de decisão, identificando os elementos sociais que interferem no processo de escolha. Para que isso aconteça, parece importante pensar uma escolha mais consciente e satisfatória, mais próxima das características pessoais e que atendam com maior veracidade suas expectativas acadêmicas e o seu desenvolvimento de carreira. Dessa forma, supõe-se que o conhecimento sobre si mesmo e sobre o contexto social no qual vive o estudante aumente a possibilidade de fazer uma escolha acertada (Ferreira et al., 2013). Levando em consideração os poucos estudos de natureza qualitativa encontrados sobre o tema expectativas acadêmicas relacionadas à carreira, este estudo se debruça no discurso dos estudantes universitários, com o intuito de oferecer uma análise dos relatos que traduzem suas experiências no Ensino Superior com destaque em dois objetivos: identificar as expectativas relacionadas à escolha profissional e as influências sociais que estão subjacentes às suas escolhas.

\section{Método}

A escolha pela metodologia qualitativa de Análise de Conteúdo (Bardin, 2011) deveu-se ao fato de ser a mais adequada, visto que permite a investigação de opiniões, sentimentos e conflitos dos sujeitos em profundidade. Sendo assim, com esse tipo de método, pressupõe-se, através das significações que os sujeitos atribuem a determinado aspecto de sua vida, a possibilidade de se chegar a indicativos de seus modos de funcionamento subjetivo e, consequentemente, de suas ações. A utilização da Análise de Conteúdo prevê três fases fundamentais: a pré-análise, a exploração do material e o tratamento dos resultados - a inferência e a interpretação.

\section{Participantes}

Fizeram parte do estudo cinco estudantes, dois do sexo masculino e três do feminino, entre 18 e 32 anos de idade, de períodos iniciais (entre o $2^{\circ}$ e o $5^{\circ}$ ) do Ensino Superior de universidades públicas e privadas do estado do Rio de Janeiro. A amostra foi de conveniência e participaram aqueles que se encontravam disponíveis nos campi das universidades e que, após terem sido convidados, concordaram em participar voluntariamente do estudo. No tratamento dos dados, a fala dos sujeitos foi identificada por números a fim de resguardar seu anonimato. O número de participantes foi determinado uma vez que se atingiu a saturação temática.

\section{Instrumento}

Foi utilizada uma entrevista semiestruturada, construída especialmente para este estudo, com o objetivo de explorar e identificar, no discurso dos estudantes, as suas diferentes expectativas acadêmicas relacionadas à carreira profissional e às possíveis influências sociais relativas à escolha do curso. Os itens da entrevista emergiram a partir da literatura com destaque para o modelo sociocognitivo de French e Raven (1959), bases do poder social e, posteriormente, levados à avaliação crítica de três professores/ juízes da área de pesquisa qualitativa. O roteiro construído com 20 perguntas semiabertas levou em consideração dois temas relacionados aos objetivos do estudo: (a) a escolha profissional e as expectativas relacionadas ao curso/carreira e mercado de trabalho e (b) a percepção das possíveis influências sociais.

\section{Procedimentos}

Os participantes foram selecionados intencionalmente, abordados nos campi das universidades $\mathrm{e}$ 
convidados a participar da entrevista. Após a explicação do objetivo da pesquisa, responderam ao Questionário Critério Brasil da Associação Brasileira de Empresas de Pesquisas (2015), que avalia o nível socioeconômico. Finalmente, foi solicitado que falassem sobre situações relacionadas às suas expectativas em relação ao curso e à carreira que, naquele momento, escolheram fazer. As entrevistas duraram em torno de 60 minutos e foram transcritas na íntegra e analisadas a partir do método de Análise de Conteúdo. As falas dos participantes foram categorizadas levando-se em conta dois critérios: expectativas relacionadas à escolha profissional e influências sociais percebidas em relação à sua escolha profissional tais como: família, amigos, professores, informação e conhecimento e, por fim, o autoconhecimento. Todos os participantes assinaram o Termo de Consentimento Livre e Esclarecido a fim de que fosse reservado o direito do anonimato e foram dados os devidos esclarecimentos do estudo. O estudo foi encaminhado e aprovado pelo Comitê de Ética em Pesquisa da Universidade na qual os pesquisadores estão vinculados.

\section{Resultados e Discussão}

Algumas categorias foram identificadas, apontando para dois tipos de resultados. O primeiro voltado para as expectativas acadêmicas dos estudantes relacionadas à carreira/curso/mercado de trabalho, tais como: (a) fatores pessoais identificação/motivação; (b) expectativas sobre grade curricular, forma de funcionamento da universidade, sobre as possibilidades de aprendizagem que a faculdade lhe oferece; (c) em relação ao futuro, relacionadas ao desejo/planejamento de dar continuidade aos estudos através de pós-graduação; conhecimento das áreas de atuação de sua futura profissão e entrada no mercado de trabalho. $\mathrm{O}$ segundo, para as possíveis influências sociais na escolha profissional tais como: família, amigos, professores, informação e autoconhecimento.

Desmistificando a ideia de que a escolha profissional é feita para a vida toda e identificando os fatores internos (expectativas) e externos ao sujeito (influência sociais), que o levam a escolher determinada carreira, pôde-se perceber que os primeiros revelam algumas expectativas acadêmicas relacionadas à carreira/curso e a forma como são construídas através das experiências estudantis anteriores.

Escolhi Letras por gostar de língua portuguesa. Eu gostava tanto das aulas de uma professora no Ensino Médio que acabei seguindo ela. (sujeito 4, comunicação pessoal, $2^{\circ}$ período).
Eu tive um professor de química que eu enchia ele de perguntas, toda vez depois da aula eu perguntava alguma coisa a ele e aí, fui me tocando que isso não era só daquela época, eu sempre perguntava muita coisa a todo mundo, como as coisas funcionam...Ai eu fiquei meio assim... Meu Deus, química? (sujeito 2, comunicação pessoal, $4^{\circ}$ período).

Ainda sobre as expectativas, todos os entrevistados se mostraram satisfeitos com o curso em que estavam inseridos o que demonstrou ser um indicador importante para o planejamento de projetos futuros. Além de satisfeitos, mostraram conhecer o modo de funcionamento acadêmico do seu curso, as disciplinas existentes, as possibilidades de estágio e a estrutura da instituição. Alguns desses elementos podem ser observados na fala seguinte.

O curso correspondeu bastante às minhas expectativas. Uma coisa que acho interessante é que o currículo está sempre mudando. Entrei, era um currículo, agora ele foi dividido em duas áreas de concentração. Aí, as matérias mudam para otimizar, focar mais nos pontos especificos. Eles tiraram um pouco das disciplinas Obrigatórias, que eram irrelevantes para o curso e que eram relevantes para Engenharia Química, e eles colocaram esses créditos para Optativas Obrigatórias. Nessas, você pode pegar matérias do Mestrado (sujeito 2, comunicação pessoal, $4^{\circ}$ período).

Embora a satisfação das próprias expectativas quanto ao curso escolhido tenha se mostrado clara em relação às possibilidades de desenvolvimento de carreira, é importante destacar que os reflexos da escolha profissional e das expectativas geradas no estudante, ao longo de seu percurso acadêmico, podem ser de natureza pessoal, familiar, social, econômica e educacional/acadêmica. Neste estudo, destaca-se o papel da família, dos professores, dos amigos e do autoconhecimento, resultado que corrobora as pesquisas de Bright, Pryor, Wilkenfeld e Earl, (2005); Pereira e Garcia, (2007) e das diferenças geracionais apontadas nos estudos de Cordeiro, Freitag, Fischer e Albuquerque (2013); Ferreira et al. (2013); Herr (2008).

No presente estudo, a maioria dos entrevistados relata ter tido apoio da família na sua escolha profissional, mas antes do apoio, alegam ter sofrido pressão dos pais em relação à escolha da profissão. Segundo os entrevistados, seus pais tenderam a orientá-los de acordo com a profissão que exerciam ou direcionavam-nos por uma preocupação relacionada a fatores financeiros e estabilidade profissional. Observa-se a influência exercida pelos 
amigos, professores e pelo universo de informações aos quais as pessoas hoje tem acesso. No entanto, pode-se dizer que, neste estudo, a ação dos fatores externos (influência de familiares, professores e amigos) sobre o pessoal não anulou os interesses dos entrevistados pelo curso que escolheram. Eles "aceitaram" as ideias externas, vindas de pais, amigos e professores; contudo não de forma passiva, fizeram delas uma forma de buscar informações e mapear seus próprios interesses.

Minha familia me achou louca quando disse que ia fazer Pedagogia, que eu deveria fazer Contabilidade, que no caso, toda a minha família fez, mas minha mãe me apoiou (...) meus amigos me chamaram de louca, que eu ia ganhar pouco, ser professora. Muitos amigos fizeram os cursos de Administração, Contabilidade. É a ideia que as pessoas têm de alguns cursos, que não são muito valorizados. Realmente não são. Você tem que se esforçar mais do que as outras pessoas para conseguir a mesma coisa, o mesmo retorno financeiro. (sujeito 1 , comunicação pessoal, $5^{\circ}$ período).

Como afirmam Paula, Dutra e Vilas Boas (2014), a influência da família é, muitas vezes, determinante na escolha, podendo ou não estar de acordo com os reais desejos e a vocação do adolescente. No entanto, ao contrário do que se pode esperar, guiados por um maior autoconhecimento do que gostam ou não de fazer, tentaram mediar o desejo dos pais e sua própria vontade a fim de fazer, à medida do possível, o curso que mais se aproximava do seu perfil e das suas expectativas acadêmicas.

Lá pro final do Ensino Médio, não tive muito apoio dos meus pais para fazer Música, que era o que eu queria. Tive apoio, mas parecia que ia ser Ciência da Computação mesmo, só que nunca fui muito bom em matemática. Então pesquisando, a gente achou o curso de Mídia Digital dentro do curso de Design, que parecia ser um curso que tinha espaço para criar. Nesse curso, parecia que eu podia fazer jogos e ainda com algo relacionado à música. (sujeito 3, comunicação pessoal, $5^{\circ}$ período).

Por outro lado, se a família exerce uma influência inegável e inevitável na escolha da carreira dos filhos, ela também pode contribuir para a abertura de novos olhares sobre a profissão e o mercado de trabalho, minimizando as expectativas fantasiosas que o adolescente porventura tenha no tocante à realidade acadêmica e à carreira escolhida. Nesse sentido, os familiares podem servir de ferramenta para aumentar o nível informacional e o comportamento exploratório e, com isso, ajudar a minimizar a distância entre o real e o imaginário desses estudantes (Bardagi, Lassance, \& Teixeira, 2012). Como afirmam os mesmos autores, o suporte e o encorajamento oferecidos pela família sustentam o comportamento exploratório (Teixeira, Bardagi, \& Hutz 2007; Teixeira \& Dias, 2011) e, consequentemente, a construção de uma carreira, como pode ser percebido na fala a seguir.

Meu pai sempre me incentivou a fazer Direito, devido à minha capacidade argumentativa muito forte, mas, quando, no final das contas, eu decidi fazer Artes, ele não proibiu e apoiou; a minha mãe também, apesar de pensar que eu poderia fazer Arquitetura como ela, ou Jornalismo, que era uma das minhas opções também, já que eu gosto muito de escrever e escrevo bem. Sempre fui muito ligada à arte, principalmente à pintura e ao desenho, por isso pensei em seguir carreira nessa área. (sujeito 5 , comunicação pessoal, $2^{\circ}$ período).

Pra mim, a maior influência mesmo foram meus pais. Não que eu fui forçado pelos meus pais. Há uma certa expectativa dos pais, né! Eles querem o melhor para seus filhos. Então, infelizmente, certas carreiras são menos instáveis, menos incertas, né... A carreira de médico, engenheiro são coisas garantidas... mais ou menos, né... (sujeito 3 , comunicação pessoal, $5^{\circ}$ período).

Como foi visto, a família contribui no processo de escolha da carreira, seja como suporte informacional ou emocional, normalmente denominado de verticalizado. Porém é importante considerar que os amigos, por vivenciarem momentos semelhantes, também podem exercer uma relevante influência nesse processo (Pereira \& Garcia, 2007). A identificação com seus pares também funciona como suporte emocional sendo esta considerada horizontal (Pereira \& Garcia, 2007).

Embora a opinião dos amigos sobre a decisão profissional dos seus semelhantes pudesse ter contribuído no processo de escolha do curso, já que, na maioria das vezes, o estudante nesse momento está ainda indeciso (Faria \& Taveira, 2006; Lassance, Bardagi, \& Teixeira, 2009; Sparta, 2003) e acaba por seguir o que os colegas fazem, no presente estudo, a avaliação dos amigos não foi um aspecto forte a ponto de fazê-los mudar a sua escolha inicial pelo curso. Os estudantes entrevistados mostraram-se bastante certos do que queriam fazer e não se deixaram levar por opiniões diferentes 
das suas como se pode perceber nas falas apresentadas indicando a contribuição do autoconhecimento no processo de decisão.

Meus amigos acreditavam que eu poderia tentar um curso considerado mais dificil que também conseguiria. Mas sabiam que a Arte tinha tudo a ver comigo e diziam que eu realmente havia nascido para isso, que era o meu talento, então, me apoiaram. (sujeito 5 , comunicação pessoal, $2^{\circ}$ período).

Química? Você é maluco? Por que todo mundo acha que a química que tô vendo é do Ensino Médio, que todo mundo vai mal, reprova? Mas não é nada disso! (sujeito 2 , comunicação pessoal, $4^{\circ}$ período).

O discurso dos entrevistados corrobora, em parte, os resultados obtidos na pesquisa de Pereira e Garcia (2007) a qual identificou a influência relativa dos amigos na vida dos estudantes através de conversas e troca de informações. Neste estudo, foi possível observar que também houve a atuação dos amigos no processo de escolha, quando, por exemplo, suas opiniões foram emitidas, o que reforçou a ideia da atuação ser horizontal, de natureza informacional (Pereira \& Garcia, 2007).

Assim, como a qualidade das relações estabelecidas entre os adolescentes, sua família e seus amigos, a relação com os seus professores também pode contribuir, positiva ou negativamente, no processo de escolha profissional. É sabido que professores carismáticos tendem a atrair a atenção de jovens que, consequentemente, interessam-se pelas disciplinas por eles lecionadas, facilitando processos de aprendizagens, tornando-os atrativos para o estudante e, inevitavelmente, para o processo de escolha profissional. Nesse contexto, os professores são figuras fundamentais de apoio e desafio a construção vocacional (Ferreira, Nascimento, \& Fontaine, 2009).

Nesse sentido, para parte dos sujeitos entrevistados, as experiências estudantis anteriores, tais como a opinião ou as atitudes dos professores, especialmente do Ensino Médio, funcionaram como uma referência profissional, com os quais se identificaram e puderam ter um maior aprendizado com disciplinas específicas.

Escolhi Letras por gostar de lingua portuguesa. Eu gostava tanto das aulas de uma professora no Ensino Médio que acabei seguindo ela. (sujeito 4, comunicação pessoal, $2^{\circ}$ período).

Eu quis escolher Química por causa do professor. Ele falava além, ele me explicava como as coisas eram antes de chegar ao funcionamento. Depois deste professor, meu destino virou assim. (sujeito 2 comunicação pessoal, $4^{\circ}$ período).

Nas falas apresentadas, pôde-se observar que professores são uma referência estimulante aos entrevistados que procuram definir-se por uma carreira. Porém, de modo geral, a família funciona como uma referência primária nesse quesito, ou seja, o grupo familiar se apresenta mais atuante que os amigos e professores, embora, atualmente, outros fatores, tais como a facilidade de acesso à informação, também contribuam no processo de decisão. As expectativas relacionadas ao desenvolvimento profissional estão relacionadas também a um maior conhecimento sobre a profissão, englobando a difusão através dos meios de comunicação, a sua trajetória na universidade e as oportunidades existentes no mercado de trabalho, bem como a percepção sobre si mesmo, isto é, conhecimento de suas necessidades e motivações (Lent, Brown, \& Hackett, 1994; Teixeira, Bardagi, \& Hutz 2007; Teixeira \& Dias, 2011; Teixeira, 2008). O conjunto desses fatores pode indicar uma tendência, mais atual, de que os estudantes possam desenvolver expectativas mais reais diante da carreira escolhida, uma vez que há uma aproximação entre suas aspirações, o que se espera e o que se encontra de fato no curso e, posteriormente, no mercado de trabalho.

O curso de Artes dá diversas opções profissionais. Eu li sobre o curso, sobre as opções de trabalho e olhei a grade curricular. Li sobre os cursos de Artes Visuais (Licenciatura) e Artes Plásticas (Bacharelado) para escolher o que mais atendia às minhas aspirações. Seu ponto forte é em formar pesquisadores, o que acho excelente. (sujeito 5 , comunicação pessoal, $2^{\circ}$ período).

Hoje estou trabalhando no Laboratório de Sintese Orgânica e o foco é o desenvolvimento de fármaco anticâncer (...) isso é o máximo! Eu não tenho projeto ainda definido, pois entrei no começo desse ano, estou tomando conhecimento das coisas, mas acho que, em agosto, eu começo, pois ganhei uma bolsa PIBIC (...) Eu quero seguir a carreira acadêmica, fazer mestrado em Educação. Eu me vejo continuando na pesquisa e dando aula, que, aliás, já dou em um pré-vestibular comunitário na Gávea. Não me vejo trabalhando em indústrias por causa dessa lógica de mercado que eu não concordo, acho que eu não preciso disso. (sujeito 2 , comunicação pessoal, $4^{\circ}$ período). 
A partir das falas, pode-se também concluir que os sujeitos fizeram suas escolhas estimulados por elementos que fazem parte do conceito de expectativas acadêmicas. São eles: a motivação e o comportamento exploratório, associado à busca de informações e a projetos futuros, tendo como cenário as relações estabelecidas com familiares, principalmente os genitores, com os amigos mais próximos e com os professores com os quais se identificam.

A percepção sobre seus anseios e autoconhecimento, adicionados à aquisição de informações sobre a realidade profissional, através da Internet, revistas especializadas e guias sobre profissões, foi uma característica que esteve presente nas falas dos entrevistados relacionadas às expectativas do curso e à escolha da carreira. Tal atitude facilitou o processo de escolha em relação à profissão, bem como contribuiu para diminuir a lacuna existente entre as expectativas fantasiosas e reais sobre os mesmos. Pelo menos, parte dos estudantes entrevistados mantiveram suas escolhas iniciais, visto que, mesmo diante da opinião de terceiros, mantiveram-se fiéis às suas preferências. Esses elementos fomentam o modelo sociocognitivo de escolha profissional que contempla as aprendizagens e experiências internalizadas ao longo do seu desenvolvimento e autoconhecimento (Lent, Brown, \& Hackett, 1994; Teixeira, 2008).

\section{Considerações finais}

Este estudo indica que parte dos estudantes universitários entrevistados sabe, com bastante clareza, o que querem em relação ao seu futuro profissional e buscam informações com mais facilidade provavelmente devido à maior acessibilidade à informação. Além disso, começam a reconhecer suas próprias características, necessidades e desejos, categoria denominada aqui como autoconhecimento. Sendo assim, formam sua própria visão de como desejam e esperam que seja sua vida acadêmica e profissional, não se deixam influenciar facilmente pela família, amigos ou por um discurso social ainda muito conservador no que se refere à escolha de profissões mais tradicionais, embora isso ainda aconteça. Diante desse contexto, este estudo contribui para reforçar a importância do autoconhecimento, aspecto que vem crescendo, mesmo que timidamente, e sendo cada vez mais considerado pelos estudantes. Assim, o reconhecimento e a valorização das suas próprias características, aptidões e habilidades, necessidades e desejos tendem a contribuir para uma escolha mais realista da carreira.

Assim, antes de dar continuidade às reflexões finais, cabe especificar que os resultados foram considerados em dois níveis: conhecimento e informação adquiridos sobre o curso, carreira, mercado, seguindo o modelo teórico de influências sociais proposto por French e Raven (1959) e Raven (1993) e o conhecimento sobre si mesmo, considerado principal contribuição deste estudo. Portanto, o autoconhecimento pode expressar o conhecimento, mesmo que de forma superficial, das características pessoais tais como aptidões, habilidades, necessidades e aspirações do sujeito em relação a um objeto específico. Tal categoria surgiu a partir das entrevistas e não é proposta teórica no modelo de French e Raven. Não obstante, sendo esta uma pesquisa de cunho qualitativo e exploratório, como ferramenta metodológica, não foi possível medir o quanto esse construto, o autoconhecimento, realmente influenciou ou se relacionou com o referido modelo no que diz respeito ao desenvolvimento das expectativas de carreira. O que se pode concluir é que as falas dos sujeitos indicam elementos ("sempre tive vontade", "tenho vocação para", "me dei conta que eu sempre gostei de") os quais nos apontam que saber sobre suas vontades, desejos, aspirações mostra um nível inicial de conhecimento sobre si mesmo, pelo menos, no que diz respeito aos estudantes entrevistados neste estudo. Os universitários demonstram certa segurança com suas escolhas iniciais, sentimento que pode contribuir para a diminuição da lacuna entre o que realmente se configura e suas expectativas muitas vezes pouco realistas, questão que é apresentada de forma recorrente em vários estudos (Gomes \& Soares, 2013; Hernández \& Pérez, 2010).

$\mathrm{O}$ autoconhecimento, adicionado a um maior acesso à informação através dos pais, amigos, professores e profissionais da área, permitiu alinhar o conhecimento que tinham sobre a realidade da profissão às suas necessidades, uma vez que demonstraram ter maior entendimento sobre si mesmos. Tal movimento, ainda um pouco tímido, ganha espaço diante das pressões exercidas pela sociedade como um todo para a escolha de carreiras mais tradicionais e valorizadas.

Entre as limitações, verifica-se um número pequeno de sujeitos entrevistados, conduta que torna o resultado pouco generalizável. Outro aspecto que deve ser considerado é o fato de que na amostra deste estudo prevaleceram participantes de classe social média e alta o que pode ter facilitado o acesso à informação e contribuído para um processo de escolha de carreira, com maior liberdade, de forma mais confortável voltado para seus próprios desejos e necessidades uma vez que eles desfrutam de boa condição/status familiar e não precisaram, até o momento, trabalhar para se manter. É interessante que se leve em consideração a origem social, já que questões como influências sociais, família, amigos, professores e informação podem se diferenciar entre as classes sociais. Essas podem 
evidenciar diferenças significativas no que diz respeito à orientação oferecida pela família, em relação aos interesses entre os pares, ao estímulo dados pelos professores, bem como, ao acesso informacional sobre a carreira.

\section{Referências}

Aguiar, F. H. R., \& Conceição, M. I. G. (2009). Expectativas de futuro e escolha vocacional em estudantes na transição para o ensino médio. Revista Brasileira de Orientação Profissional, 10(2), pp. 105-115. Recuperado em 19 julho 2016, de http://pepsic.bvsalud.org/pdf/rbop/v10n2/v10n2a11.pdf

Araújo, A. M., Almeida, L. S., Costa, A. R., Alfonso, S., Conde, A., \& Deaño, M. (2015). Variáveis pessoais e socioculturais de diferenciação das expectativas académicas: Estudo com alunos do Ensino Superior do Norte de Portugal e Galiza. Revista Portuguesa de Educação, 28(1), 201-220.

Associação Brasileira de Empresas de Pesquisas. (2015). Critério de classificação econômica Brasil. Recuperado em 20 julho 2016, de http://www.abep.org/criterio-brasil

Bardagi, M. P., Lassance, M. C. P., \& Paradiso, A. C. (2003). Trajetória acadêmica e satisfação com a escolha profissional de universitários em meio de curso. Revista Brasileira de Orientação Profissional, 4(1-2), 153-166. Recuperado em 22 julho 2016, de http://pepsic.bvsalud.org/pdf/rbop/v4n1-2/v4n1-2a13.pdf

Bardagi, M. P., Lassance, M. C. P., \& Teixeira, M. A. P. (2012). O contexto familiar e o desenvolvimento vocacional de jovens. In M. N. Baptista \& M. L. M. Teodoro (Orgs.), Psicologia de família: Teoria, avaliação e intervenções (pp. 135-144). Porto Alegre, RS: Artmed.

Bardin, L. (2011). Análise de Conteúdo. São Paulo: Edições 70.

Berger, P. L., \& Luckmann, T. (2004). A construção social da realidade: Tratado de sociologia do conhecimento. Petrópolis: Vozes.

Bright, J. E. H., Pryor, R. G. L., Wilkenfeld, S., \& Earl, J. (2005). The role of social context and serendipitous events in career decision making. International Journal for Educational and Vocational Guidance, 5, 19-36. DOI: 10.1007/ s10775-005-2123-6

Castro, L. M. H. M., Nishimura, A. T., Silva, C. M., Madureira, B. M., \& Casado, T. (2007). Expectativas e satisfação dos alunos de graduação em administração da FEA-USP/SP em relação aos estágios. Revista de Gestão USP, 14(edição especial), 61-76. DOI: 10.5700/issn.2177-8736.rege.2007.36582

Cordeiro, H. T. D., Freitag, B. B., Fischer, A. L., \& Albuquerque, L. G. (2013). A questão das gerações no campo da gestão de pessoas: Tema emergente? Revista de Carreiras e Pessoas, 3(2), 2-18. DOI: http://dx.doi.org/10.20503/recape. v3i2.16531

Faria, L. \& Loureiro, N. (2015). Aconselhamento de carreira multicultural: Abordagens teóricas e implicações para a prática. Revista Brasileira de Orientação Profissional, 16(1), 11-21. Recuperado em 25 julho 2016, de http://pepsic. bvsalud.org/pdf/rbop/v16n1/03.pdf

Faria, L., \& Taveira, M. do C. (2006). Avaliação da exploração e da indecisão de jovens no contexto da consulta psicológica vocacional: Um estudo da eficácia da intervenção. In C. Machado et al. (Eds.), Actas da $11^{\circ}$ Conferência Internacional Avaliação Psicológica: Formas e Contextos (pp. 1-16). Braga: Psiquilibrios. Recuperado em 25 julho 2016, de http://hdl.handle.net/1822/7444

Felix, G. M. (2013). Transferência interna é alternativa para quem repensa escolha do curso. Educação USP Online Destaque. Recuperado em 25 julho 2016, de http://www5.usp.br/22074/ transferencia-interna-da-usp-e-alternativa-para-quem-repensa-escolha-do-curso/.

Ferreira, A. F., Nascimento, I., \& Fontaine, A. M. (2009). O papel do professor na transmissão de representações acerca de questões vocacionais. Revista Brasileira de Orientação Profissional, 10(2), 43-56. Recuperado em 25 junho 2016, de http://pepsic.bvsalud.org/pdf/rbop/v10n2/v10n2a06.pdf

Ferreira, S. I., Saavedra, L., Taveira, M. C., \& Araújo, A. M. (2013). Escolhas e planejamento de carreira: A tirania dos discursos tradicionais. Revista Brasileira de Orientação Profissional, 14(2), 165-175. Recuperado em 25 junho 2016, de http://pepsic.bvsalud.org/pdf/rbop/v14n2/03.pdf

French, J. P., \& Raven, B. H. (1959). The bases of social power. In D. Carwright, (Org.), Studies in social power. Ann Arbor: Institute for Social Research.

Freund, A., Cohen, A., Blit-Cohen, E., \& Dehan, N. (2013). Professional socialization and commitment to the profession in social work students in Israel. Management Education \& Development, 1(13727). DOI: 10.5465/AMBPP.2013.13727abstract 
Gadassi, R., Gati, I., \& Dayan, A. (2012). The adaptability of career decision-making profiles. Jounal of Counseling Psychology, 59(4), 612-622. DOI: doi.org/10.1037/a0029155

Gati, I. (2013). Advances in career decision making. In W. B. Walsh, M. L. Savickas, \& P. J. Hartung (Eds.), Handbook and vocational psychology: Theory, research and pratice (pp. 183-216). New York: Routledge.

Gomes, G., \& Soares, A. B. (2013). Inteligência, habilidades sociais e expectativas acadêmicas no desempenho de estudantes universitários. Psicologia: Reflexão e Crítica, 26(4), 780-789. DOI: https://dx.doi.org/10.1590/ S0102-79722013000400019

Hernández, G. H., \& Perez, J. A. F. (2010). Expectativas profesionales: Um estudio de caso. Revista Mexicana de Orientação Educacional, 7(19), 18-27.

Herr, E. (2008). Social contexts for career guidance throughout the world. In J. A. Athanasou \& R. Esbroeck (Eds.), International Handbook of Career Guidance (pp. 45-94). New York, NY: Springer Publishing.

Hila, A. B. C. (2014). Juventud, trabajo y desempleo em los prolegómenos de la crisis económica em España: Reflexiones críticas. Acta Sociológica, 64, 99-120. DOI: 10.1016/S0186-6028(14)70484-0

Jordaan, J. P. (1963). Exploratory behavior: The formation of self and occupational concepts. In D. Super, R. Starishevsky, N. Matlin \& J. P. Jordaan (Eds.), Career development: Self concept theory: Essays in vocational development (pp. 42-78). New York: College Entrance Examination Board.

Lassance, M. C. P., Bardagi, M. P., \& Teixeira, M. A. P. (2009). Avaliação de uma intervenção cognitivo-evolutiva em orientação profissional com um grupo de adolescentes brasileiros. Revista Brasileira de Orientação Profissional, 10(1), 23-32. Recuperado em 29 setembro 2017, de http://pepsic.bvsalud.org/pdf/rbop/v10n1/v10n1a05.pdf

Lent, R. W., Brown, S. D., \& Hackett, G. (1994). Towards a unifying social cognitive theory of career and academic interests, choice and performance. Journal of Vocational Behavior, 45(1), 79-122. DOI:10.1006/jvbe.1994.1027

Marinho-Araújo, C. M., Fleith, D. S., Almeida, L. S., Bisinoto, C., \& Rabelo, M. L. (2015). Adaptação da escala de expectativas acadêmicas de estudantes ingressantes no Ensino Superior. Avaliação Psicológica, 14(1), 133-141. DOI: $10.15689 /$ ap.2015.1401.15

Merhi, R. (2011). Expectativas del estudiantado en la universidad del nuevo milenio. Un proceso dinâmico. La Cuestión Universitaria, 7, 2011, p. 23-31.

Nadelson, L. S., Semmelroth, C., Martinez, G., Featherาstone, M., Fuhriman, C. A., \& Sell, A. (2013). Why did they come here? The influences and expecta $\neg$ tions of first-year students' college experience. Higher Education Studies, 3(1), 50-62. DOI: 10.5539/hes.v3n1p50.

Neiva, K. M. C. (2013). Processos de escolha e orientação profissional. São Paulo: Vetor.

Oliveira, C. T. \& Dias, A. C. G. (2013). Percepções parentais sobre sua participação no desenvolvimento profissional dos filhos universitários. Revista Brasileira de Orientação Profissional, 14(1), 61-72. Recuperado em 29 setembro 2017 , de http://pepsic.bvsalud.org/pdf/rbop/v14n1/07.pdf

Paula, A. V., Dutra, A. M., \& Vilas Boas, A. A. (2014). Percepções de adolescentes e seus cuidadores quanto ao nível de maturidade para escolha profissional: um estudo de caso. Revista FSA, 11(4), 206-218. Recuperado em 04 agosto 2016, de www4.fsanet.com.br/revista/index.php/ fsa/article/download/634/369.

Pereira, F. N. E., \& Garcia, A. (2007). Amizade e escolha profissional: Influência ou cooperação? Revista Brasileira de Orientação Profissional, 8(1), 71-86. Recuperado em 29 setembro 2017, de http://pepsic.bvsalud.org/pdf/rbop/v8n1/ v8n1a07.pdf

Raven, B. H. (1993). The bases of power: Origins and recent developments. Journal of Social Issues, 49(4), 227-251. DOI: $10.1111 /$ j.1540-4560.1993.tb01191.x

Sparta, M. (2003). A exploração e a indecisão vocacionais em adolescentes no contexto educacional brasileiro. (Dissertação de Mestrado em Psicologia do Desenvolvimento), Universidade Federal do Rio Grande do Sul, Porto Alegre.

Setton, M. G. J. (2011). Teorias da socialização: Um estudo sobre as relações entre indivíduo e sociedade. Revista Educação e Pesquisa, 37(4), 711-724.

Soares, A. B., Francischetto, V., Dutra, B. M., Miranda, J. M., Nogueira, C., Leme, V. R., Almeida, L. S. (2014). O impacto das expectativas na adaptação acadêmica dos estudantes no Ensino Superior. Psico, 19(1), 49-60. DOI: $10.1590 / \mathrm{S} 1413-82712014000100006$

Soares, A. P. C., \& Almeida, L. S. (2001). Transição para a universidade: apresentação e validação do questionário de expectativas acadêmicas (QEA). In B. D. da Silva \& L. S. Almeida (Eds.). Actas do $6^{\circ}$ Congresso Galaico-Português de Psicopedagogia, (pp. 899-909). Braga: Universidade do Minho. 
Soares, D. H. P. (2002). A escolha profissional do jovem adulto. São Paulo: Summus.

Super, D. E. (1963). Vocational development in adolescence and early adulthood: Tasks and behaviors. In D. E. Super, R. Starishevsky, N. Martin, \& J. P. Jordaan, Career development: Self concept theory: Essays in vocational development (pp.79-95). New York: College Entrance Examination Board.

Super, D. E. (1990). A life-span, life-space approach to career development. In D. Brown, L. Brooks, \& Associates (orgs.), Career choice and development (pp. 197-261). San Francisco: Jossey-Bass.

Super, D. E., Savickas, M. L., \& Super, C. M. (1996). The life-span, life-space approach to careers. In D. Brown, L. Brooks, \& Associates (Orgs.), Career choice and development (pp. 121-178). San Francisco: Jossey Bass.

Teixeira, M. O. (2008). A abordagem sócio-cognitiva no aconselhamento vocacional: Uma reflexão sobre a evolução dos conceitos e da prática da orientação. Revista Brasileira de Orientação Profissional, 9(2), 9-16. Recuperado em 29 setembro 2017, de http://pepsic.bvsalud.org/pdf/rbop/v9n2/v9n2a03.pdf

Teixeira, M. A. P., Bardagi, M. P., \& Hutz, C. S. (2007). Escalas de exploração vocacional (EVV) para universitários. Psicologia em Estudo, 12(1), 195-202.

Teixeira, M. A. P., \& Dias, A. C. G. (2011). Escalas de exploração vocacional para estudantes de ensino médio. Estudos de Psicologia, 28(1), 89-96.

Zanotelli, R. C. (2009). Professores do Ensino Superior frente às novas tecnologias: Usos e desusos do computador e da Internet no cotidiano do trabalho (Tese de Doutorado em Psicologia), Pontifícia Católica do Rio de Janeiro, Rio de Janeiro.

Recebido: $15 / 02 / 2017$

$1^{a}$ reformulação: 19/08/2017

Aceite final: 30/08/2017

Sobre as autoras

Reivani Chisté Zanotelli Buscacio é Professora da Universidade Veiga de Almeida. Doutora pela Pontifícia Universidade Católica do Rio de Janeiro e Pós Doutora pela Universidade Salgado de Oliveira.

Adriana Benevides Soares é Professora titular da Universidade Salgado de Oliveira e professora associada da Universidade do Estado do Rio de Janeiro. Doutora pela Universidade de Paris XI e Pós Doutora pela UFSCar. 